\title{
Istok - Zapad - Rusija, ili SAD kao metafora
}

Rusku kulturu gotovo od samih početaka snažno je definirao odnos prema Zapadu - zapadnjačkim vrijednostima, mitologiji, svakodnevici, ekonomiji, kulturi, politici, društvenom uređenju. Od jedne od svakako prijelomnih točki, razaranja Velikog Novgoroda tijekom moskovsko-novgorodskog rata (1477. - 1478.), i pripajanja ondašnjoj ruskoj državi toga grada, koji se je od Moskve razlikovao ekonomskom i vjerskom organizacijom te organizacijom političke hijerarhije, dijalektički razvoj ruske povijesti u mnogome određuje napetost između zapadnjačkih (europskih i kasnije sjevernoameričkih) i ruskih (istočnih ili slavenofilskih) tendencija. Crkveni raskol u 17. stoljeću, s patrijarhom Nikonom i protopopom Avvakumom kao predstavnicima dviju suprotstavljenih tabora; inzistiranje Petra Velikoga na reformama u „europskome duhu” i na podizanju grada po uzoru na europske prijestolnice, premještanje središta države iz „zaostale”, „seoske”, „izolirane”, „tradicionalne” i „konzervativne” Moskve u „progresivan”, „urban”, „otvoren”, „liberalan” Peterburg; „zapadnjaci” i „slavenofili” s kraja 30-ih i početka 40-ih godina 19. stoljeća kao kulminacijske točke stoljeće i pol dugog dijaloga između različitih poimanja ispravnoga smjera ruskoga progresa - sve su to samo neki od za rusku intelektualnu povijest ključnih točaka razvoja. U 20. stoljeću napetost između Zapada i Istoka posebno se izoštrava, s jedne strane, naglim i oštrim reformama sovjetskih vlasti u svim poljima individualnog i kolektivnog života, a s druge činjenicom da su te reforme često bile objašnjavane i prezentirane kao neizbježna nužnost, preduvjet u procesu kreiranja sovjetskog i socijalističkog/komunističkog kao prostora razlike u odnosu na novog demonskog neprijatelja kapitalističke Sjedinjene Američke Države. Leninove riječi „dostići i prestići” („dognat' i peregnat"” civilizaciju SAD-a u ekonomskom i tehnološkom smislu) osobito su zaoštrene kada im se, prvo kod Lenina, a potom i Stalina, suprotstavlja tragična smrt kao jedina druga opcija („ili ćemo poginuti, ili ćemo doseći i nadići”), one nalaze i na svoj odjek u književnosti (primjerice, u poeziji Majakovskog) te ih se s posebnim zamahom aktualizira tijekom kasnog socijalizma i Hruščevljeve vladavine. Nixon i Hruščev su se tijekom tzv. kuhinjskih rasprava na trenutke smiješnom političkom retorikom 
natjecali oko toga koji je sustav nadmoćniji, emigracija postaje sve brojnija, a hladnoratovski sukob - i u financijskom i u političkom smislu - kulminira u tzv. svemirskoj utrci.

Zapad je u tome značenjskome kompleksu stilska figura (metafora, simbol, metonimija, alegorija), on je otvorena rana i prostor istodobnog privlačenja i duboke mržnje. Zapad je, poput Peterburga, tog „prozora u Europu”, u kolektivnoj kulturno-povijesnoj svijesti zabilježen kao unaprijed isplaniran, racionalan, stvaran, istinski, inovativan, harmoničan i jedinstven; Zapad, kao i Peterburg, postoji i živi u stvarnome, sadašnjom vremenu; Rusija je, poput Moskve, iskonska, divlja, tradicionalna, disharmonična; Rusija, kao i Moskva, postoji samo u povijesnome vremenu. Rusija je žensko i život - iracionalno, maštovito, emocionalno, apstraktno, ali i iskonsko; Zapad je muško i teorija - racionalno, znanstveno, konkretno, ali i umjetno. Hercenove riječi u ogledu Moskva i Peterburg (1842.) i danas su iznenađujuće relevantne kada razmišljamo o opoziciji Rusije i Zapada, gdje Moskva predstavlja Rusiju, a Sankt-Peterburg - Zapad, i posebice SAD: „Govoriti o sadašnjosti Rusije znači govoriti o Peterburgu, o tom gradu bez povijesti na jednoj i drugoj strani, o gradu sadašnjosti, o gradu koji živi i radi samo na razini trenutnih i ovozemaljskih potreba na golemom dijelu planete koji se naziva Rusija. Moskva, naprotiv, gleda na prošli svagdan, na svoju imaginarnu vezu s njim: ona čuva sjećanja na neku prošlu slavu, uvijek gleda unazad, zabavljena peterburškim kretanjem, ide stražnjicom prema naprijed i ne vidi europska načela zbog toga što in dodiruje potiljkom. Život je Peterburga isključivo u suvremenosti, on se ne može sjećati ničega osim Petra Prvoga, njegova je prošlost zbijena u jedno stoljeće, on nema ni povijesti ni budućnosti; svake jeseni čeka oluju koja će ga potopiti. Peterburg je hodajuća kovanica bez koje je nemoguće Živjeti; Moskva je rijetka, vjerojatno i dragocjena za numizmatičara, ali bez šanse progresa."

Književnost i filozofija s obje strane, istočne i zapadne, često su promišljale i konceptualizirale na estetskoj i etičkoj razini te dvije sfere kao prostor razlike (moguće je, dakako, govoriti i o tri sfere, jer poistovjećivanje Rusije s Istokom ni u kojem smislu nije neosporno - i Rusija ima „svoj” Istok), s općenitim dojmom da je - unatoč tomu što se i Zapad u velikoj mjeri oblikuje imajući na umu Istok, odnosno Rusiju - interes prema Zapadu veći iz smjera Rusije prema Zapadu nego obrnuto. Rusija se mjeri Zapadom češće no obrnuto. Stječe se nadalje dojam da je zanimanje Zapada za Rusiju, barem na razini masovne kulture, u pravilu dosta površno i vezano uz neki oblik „,neprilagođenosti” ili protesta (intervjui Olivera Stonea s Putinom u tom su smislu indikativni upravo zbog Stoneova 
„izvannalaženja” u odnosu na mainstream američku kulturu), uz egzotizaciju Rusije (hollywoodski filmovi čest su primjer toga, prisjetimo se, primjerice, ekranizacija i adaptacija klasične ruske književnosti) ili pak uz nedovoljno nijansirano znanje, zbog kojega se, primjerice, u suvremenoj Rusiji vide samo sjene koje na nju baca sovjetska prošlost (eklatantni je primjer film Dan nezavisnosti, sniman pet godina nakon raspada Sovjetskoga Saveza, kada se posebno izvješće iz Novosibirska odvija u sklopu programa „Soviet Central News”). Unatoč brojnoj ruskoj emigraciji, zaposlenoj na sjevernoameričkim i općenito anglojezičnim visokoškolskim institucijama, koja u velikoj mjeri oblikuje suvremeni zapadnjački diskurs o Rusiji (barem njegov akademski dio), teško je zamisliti da bi primjerice u SAD-u postojao časopis „Rusija i Zapad: dijalog kultura” (,Rossija i Zapad: dialog kul'tur"), te koja uključuje i redovite godišnje znanstvene konferencije tijekom kojih se raspravlja o nizu različitih aspekata složenoga odnosa između dviju opozicija. Posve sigurno takvo intenzivno promišljanje Zapada u Rusiji svjedoči o tome da za Rusiju pitanje odnosa prema Zapadu kao složenoj konceptualnoj metafori (u kojoj preteže odnos prema SAD-u u 20. i 21. stoljeću, a prema Europi, s naglaskom na francusku, njemačku i britansku kulturu, u ranijim razdobljima) nije samo pitanje vezano uz trenutnu geopolitičku ili ekonomsku situaciju nego je i dubinski konstitutivno za kulturnu samospoznaju Rusije u gotovo svim njezinim aspektima. Istok i Zapad nisu, kao što je pisao i P. Čaadaev, geografski prostori, nego principi, načela mišljenja, filozofske kategorije.

Tekstovi koje u hrvatskome prijevodu predstavljamo ovom prilikom bave se spomenutom problematikom na za našeg čitatelja metodološki i idejno intrigantan, inovativan i informativan način te, što je najvažnije, bez inače ne toliko rijetkog pojednostavljivanja ili stereotipiziranja. Pritom se hladnoratovska dijalektika odnosa između Rusije, odnosno Sovjetskoga Saveza, i Sjedinjenih Američkih Država, u svim tekstovima promatra u dvostrukosti, odnosno u svojoj „Iokalnosti”/,regionalnosti” i transnacionalnosti - transnacionalnosti jer se Rusija promatra u kontekstu širih kulturnih značenja i praksi, a lokalnosti jer se problemsko polje ne izdvaja iz hibridnih specifičnosti regionalne povijesti i njezinih kulturnih i intelektualnih tradicija.

Četiri teksta potpisuju tri vrlo vjerojatno najutjecajnija istraživača suvremene ruske i sovjetske kulture i književnosti. Mihail Ėpštejn zaposlen je na Sveučilištu Emory. Jedan od najplodnijih suvremenih kulturologa, književnih teoretičara i filozofa (njegova bibliografija obaseže više od 750 
jedinica) i dobitnik brojnih nagrada (govor povodom jedne od njih donosimo u prijevodu i ovom prilikom), M. Ėpštejn bavi se kulturalnom i književnom teorijom, ruskom književnošću, filozofijom i religijom, novim smjerovima u humanističkim znanostima i mogućnostima njihove praktične primjene, semiotikom, evolucijom jezika i neologizmima. Knjige i znanstvene radove objavljuje na ruskom i engleskom jeziku. Ovom prilikom ističemo sljedeće knjige: Ironija ideala. Paradoksi ruske književnosti (Ironija ideala. Paradoksy russkoj literatury, Moskva, 2015.); Solo Amore: ljubav u pet dimenzija (Solo Amore: Ljubov' v pjati izmerenijah, Moskva, 2011.); Filozofija tijela (Filosofija tela, St. Petersburg, 2006.); Postmoderna u ruskoj književnosti (Postmodern v russkoj literature, Moskva, 2005.); Nakon budućnosti: paradoksi postmodernizma i suvremene ruske kulture (After the Future: the Paradoxes of Postmodernism and Contemporary Russian Culture, Amherst, 1995.). Mark Lipoveckij pseudonim je također vrlo plodnog autora Marka Lejdermana, profesora na Sveučilištu Columbia. Bavi se književnošću kasnog socijalizma (druga polovica 20. stoljeća i prije raspada SSSR-a) te je autor jedne od prvih doktorskih disertacija o ruskom postmodernizmu (prevedeni tekst upoznaje nas s njegovim stajalištem o mogućnostima razvoja postmodernizma u ruskim, naizgled drukčijim političkim, ekonomskim i kulturnim okolnostima u odnosu na Zapad). Neke su od njegovih knjiga sljedeće: Povijest ruske književnosti (A History of Russian Literature, Oxford, 2018.); Kriza postmoderne: od Lolite do Pussy Riot (Postmodern Crises: From Lolita to Pussy Riot, Boston, 2017.), Šarmovi ciničkoga uma: transformacije trikstera u sovjetskoj i postsovjetskoj kulturi (Charms of the Cynical Reason: The Transformations of the Trickster Trope in Soviet and Post-Soviet Culture, Boston, 2011.), Performativi nasilja: književni i kazališni eksperimenti „nove drame” (Performing Violence: Literary and Theatrical Experiments of New Russian Drama, Bristol, Chicago, 2009.; Performansy nasilija: Literaturnye i teatral'nye èksperimenty „novoj dramy”, Moskva, 2012.), Ruska književnost 20. stoljeća: 1950-e - 1990-e godine (Russkaja literatura XX veka: 1950-e - 1990-e gody, s Naumom Lejdermanom, Moskva, 2001.; šest izdanja). Boris Groys filozof je, povjesničar umjetnosti i teoretičar medija čije su knjige prevedene na niz svjetskih jezika. Jedan je od vodećih svjetskih proučavatelja moskovskog konceptualizma. Njegove su najpoznatije knjige Ruski kozmizam (ur., Russian Cosmism, New York, 2018.), Politika poetike (Politika poètiki, Moskva, 2012.), Uvod u antifilozofiju (Einführung in die Anti-Philosophie, München, 2009.), Komunistički postscript (Das kommunistische postskriptum, Frankfurt am Main, 2006.), Pod sumnjom (Unter Verdacht: eine Phänomenologie der Medien, 
München, 2000.), Utopija i razmjena (Utopia i obmen, Moskva, 1993.; Gesamtkunstwerk Stalin, Moskva, 2013.), Totalna umjetnost staljinizma: avangarda, estetsko diktatorstvo i iza (The Total Art of Stalinism: Avant-Garde, Aesthetic Dictatorship, and Beyond, Princeton, 1992.).

Prevedeni se tekstovi mogu čitati iz različitih perspektiva: Grojsova, primjerice, u dijalogu sa Žižekovim Sublimnim objektom ideologije, tekst Marka Lipoveckog kao kritiku postmodernizma (neuralgične točke tendencije zapadnjačkog „svojatanja” postmodernizma jasno su vidljive kada ih se promotri iz perspektive ruskih i sovjetskih književnih praksi), no ujedno i njegovu apologiju; tekstove Ėpštejna kao dokaz da je interdisciplinarnost humanističkim disciplinama imanentna. Jedno je od mogućih čitanja i ono iz perspektive odnosa Rusije prema Zapadu (odnosno, načina na koje se Rusija pokušava (raz)otkriti kroz usporedbu sa Zapadom), posebice zbog toga što su svi autori o kojima je riječ porijeklom Rusi te su u značajnoj mjeri tom kulturom i jezičnom stvarnošću, kao i konceptualnom metaforom Zapada, oblikovani. Sva su tri autora različite diskurse o Zapadu (u rasponu od Zapada kao demonskog neprijatelja do Zapada kao „imaginarnog Drugog", kako ga antropolog Aleksej Jurčak opisuje u svojoj znamenitoj studiji Everything Was Forever - Until It Was No More), upijali - da iskoristim frazu iz ruskoga jezika - „s majčinim mlijekom". Zbog toga je prevedene tekstove moguće čitati u dvostrukom ključu: kao tekstove koji nude određene inovativne i znanstveno te metodološki uzbudljive uvide u složenost odnosa između Zapada, odnosno SAD-a, i Rusije, ali i kao tekstove koji tu razliku i dijalektiku istodobno i proizvode; sve se tekstove može čitati kao simptome autorovih osobnih pokušaja da i vlastite mitove i uvjerenja konceptualiziraju i prikažu i u lokalnom, kao što sam ranije navela, i u transnacionalnom kontekstu.

Tekstove M. Èpštejna, M. Lipoveckog i B. Grojsa prevodili su studenti 3. i 4. godine studija Ruskoga jezika i književnosti tijekom rada na kolegiju „Ruske književno-znanstvene i kulturološke ideje 20. i 21. stoljeća" (ljetni semestar akademske godine 2018/2019.). Premda se, općenito govoreći, nipošto ne može tvrditi da su studenti(ce) danas osobito zainteresirani/-e za rusku književnu i kulturalnu teoriju, a posebice za filozofiju, prijevodima su prionuli s posebnim entuzijazmom i znatiželjnošću, koji tijekom katkad mukotrpnog rada na nekim složenijim dijelovima prijevoda i unatoč drugim obavezama nisu opadali. Njihovo znanje produbljeno je na načine teško dohvatljive klasičnijim metodama podučavanja, a njihova zainteresiranost i predanost ovom 
zadatku (što će, nadamo se, primijetiti i čitatelj) još je jedna potvrda važnosti povezivanja teorijskog i predavalačkog dijela podučavanja s njihovom praktičnom primjenom.

Danijela Lugarić Vukas

\section{(c) $\frac{19(9)}{\mathrm{BY} N \mathrm{NO}}$}

Creative Commons Attribution-NonCommercial-NoDerivatives 4.0 International License 